\title{
Evolutionary Psychiatry and Higher Prevalence of Depression in Females: A New Opinion
}

\author{
Saeed Shoja Shafti* \\ Department of Psychiatry, University of Social Welfare and Rehabilitation Sciences, Razi Psychiatric Hospital, Iran
}

*Corresponding author: Saeed Shoja Shafti, Professor of Psychiatry, University of Social Welfare and Rehabilitation Sciences, Razi Psychiatric Hospital, Tehran, Iran.
Received Date: April 27, 2020

Published Date: June 29, 2020

\begin{abstract}
Summery
The most consistent finding across all of the studies on the prevalence and incidence of unipolar major depression is that it is approximately twofold more common among women than men. Although, during the last century psychoanalysis and psychodynamic psychology had founded a lot of theories with respect to psychopathology, it should be accentuated that still no hypothetical points have been supported by methodical research. Evolutionary psychology and psychiatry is based on Darwin's theory regarding evolution and sexual selection is a subtype of natural selection in which individuals compete for mates. While brains result in activities that maximize inclusive fitness, reproductive effort is to get mates, and to take care of offspring. Negative emotions exist only because they have been useful ... for human genes, even if not always for human individuals. So, determining if an emotional response is atypical necessitates knowing the circumstances it has been shaped to cope with, and whether or not that state is present. While low mood is aroused when efforts to reach a goal are proving futile, continued pursuit of an unapproachable aim can escalate low mood into clinical depression. Though evolutionary psychology and psychiatry has supposed, so far, some specific mechanisms as regards the genesis of depression in human being, according to an innovative explanation depression may result from a "passive" ongoing struggle for attainment of a favourite mate, which may foster the mentality for engagement of proximate mechanisms for generation of depression; a phenomenon similar to learned helplessness. The present article reviews the involving elements and mechanisms of the said formulation and considers a practical solution, incidentally.
\end{abstract}

Keywords: Depression, Psychoanalysis, Psychodynamic psychology, Evolutionary psychology, Evolutionary psychiatry, Evolution

\section{Introduction}

The most consistent finding across all of the studies on the prevalence and incidence of unipolar major depression is that it is approximately twofold more common among women than men [1]. Since there are no data (aside from biological-hormonal differences) that indicate that female sex by itself means increased susceptibility for depression, increased stress sensitivity, maladaptive coping strategies, and multiple social roles (all of which are frequently seen in women) and substance use conditions that may disguise depressive symptoms have been proposed for the explanation of the gender difference [2]. Along with these psychosocial ideas, recent studies show that because prior anxiety disorders are more common in women, earlier anxiety disorder may also be an important factor contributing to the higher depressive morbidity in women. Hence, gender difference in unipolar major depression looks to result from the complex interaction of the said biological and psychosocial factors [1]. Minor depressive disorder and recurrent brief depressive disorder are similarly more common among females, but the difference is not so marked as that in major depression [2]. On the other hand, in special subpopulations, like dysphoric mania, mixed depressive episode, winter depression, bipolar depression with atypical clinical features and rapid cycling bipolar disorder, as well, women are overrepresented. So, there is a clear tendency: the greater the depressive element, the upper the percentage of females [3]. 


\section{Background}

While historically and during the last century, psychoanalysis and psychodynamic psychology had founded a lot of theories with respect to psychopathology, presently other psychological schools, like evolutionary psychology and psychiatry, too, have remarkable explanations that demand sufficient consideration by researchers. In addition, both of the said schools hypothesize unconscious or semi-unconscious psychopathologic processes and mechanisms, which are involved in generation of depression. In this regard, features common to many psychoanalytic theories of depression include feelings of narcissistic injury stemming from a variety of sources, including early loss or experiences with parents supposed as traumatically un-empathic, annoying, or denying [4]. A sense of defencelessness or inadequacy in relation to these experiences, with associated fantasies of damage or castration, can contribute to this vulnerability [4]. The resulting impairment in self-esteem regulation is common to all depressed patients, who are prone to a self-image of being unlovable, injured, or laughable. Depressed patients perceive that they have either failed to live up to their desires or to their ethical principles in the ego ideal, the intrapsychic mechanism that generates sense of guilt in depression [1]. Many analysts postulate that the resulting aggression toward an unsatisfying parent, or toward the self, contributes finally to the appearance of depression. So, in depressed patients, aggression is largely self-directed [5]. Difficulties in self- esteem regulation, as well, contribute to a self-representation of being "bad" or terribly out of control, provoking the original problem in a vicious cycle, which eventually elicit a common self-assessment of being worthless and bad [6-8]. Anyhow, while psychoanalytic interpretations highlight the phenomenology of features of major depression and help to make the emotive background of the ailment more comprehensible, it should be accentuated that still no hypothetical points have been supported by methodical research [9]. Instead, evolutionary psychology and psychiatry is based on Darwin's theory regarding evolution, which has two major modules [10]. The first is the unity of all life; all individuals in all species are progenies of dynasties that go back in an endless chain to the roots of life on earth. This is phylogeny, which is now traceable via genomics. Darwin's second innovation is natural selection and how it describes adaptations. It is the only sustainable clarification for why so many aspects of organisms are well-suited to coping with life's challenges [11]. The interests of an individual and his or her genes are by and large the same. So, an allele that makes healthy long-lived phenotypes is more likely to be passed on. There is, however, an exception [12]. Mutations that decrease health, happiness, longevity, or cooperativeness will spread nevertheless if they increase the number of offspring. Sexual selection is the best sample. It is the subtype of natural selection in which individuals compete for mates, either by exhibiting extreme qualities that lead to being chosen by the other sex, or by characters that lead to triumph in compete with others of the same sex [12]. Such a trait becomes more extreme until the costs it imposes are as large as the reproductive benefits [13]. While in sexual selection mate-choosing is the main goal, with its obvious connection to reproductive success [10], for humans, competition for position, friends and group memberships also impacts reproductive success [11]. Presently, there are good evolutionary reasons why many psychiatric disorders are associated with internalizing or externalizing personality extremes. Moreover, there are good evolutionary reasons to expect constant conflicts between (id) impulses to get short-term advantages and (superego) constraints that sacrifice personal short-term gain for longer term benefits of being a preferred social partner [14]. In this regard, behavioral ecology analyses how behavior patterns influence fitness by distinguishing different categories of efforts. For example, somatic effort is to get calories and other resources to grow, sustain, and look after the body. Reproductive effort is to get mates, and to take care of offspring. Social effort is to recruit allies and to achieve status in the group. This framework offers a powerful tool clinicians can use to unpack the sources of stress, because most stress comes from inability to get a secure, sufficient supply of some resource, threat of loss of a resource, or because efforts to get one resource interfere with efforts to get another [15]. Many persons are upset because of failure to find a mate, uncertainty of a marriage, or wanting to leave a relationship. Many others are incapable to find a suitable job, anxious about losing an occupation, or feeling stuck in a situation that offers little respect [16]. The task of balancing efforts to get these various resources is constant, and imbalances create pathology [12]. Brains result in activities that maximize inclusive fitness, a term that combines the reproductive success of an individual and his or her relatives [17]. However, compared to chimpanzees, humans have a remarkable ability to selectively inhibit sexual impulses. This ability must have given a selective advantage in the context of the mating patterns that developed during human evolution [18]. Emotions, too, are special modes of operation shaped by selection to cope with the challenges that rise in circumstances that have reappeared for thousands of years [19]. Like all such responses, emotional responses can be pathologically excessive or deficient. Determining if an emotional response is atypical necessitates knowing the circumstances it has been shaped to cope with, and whether or not that state is present [20]. So, a thorough investigation of the context is essential to determine if an emotion is normal and useful, normal but useless, excessive, or deficient [21]. Low mood and anxiety are the emotions that most often cause problems [22]. While emotional states shift sensation, perception, cognition, behavior, physiology, motivation, and learning, subjective experience is just one of many aspects of an emotion [23]. One profound implication for psychiatry is that negative emotions are probably useful. Anxiety, low mood, jealousy, anger, and envy exist because our ancestors with a capacity for these emotions got a selective advantage compared with those who lacked them. Negative emotions seem pathological for the reason that they are generally associated with unpleasant conditions, and because they are so agonizing and prone to interfere with important 
daily jobs [24]. However, they exist only because they have been useful ... for human genes, even if not always for human individuals [10-12]. The value of low mood is much less obvious. In what situation can sadness or low mood be useful? If sadness is aroused by a loss, than it helps to recover, replace, or otherwise adjust to a loss. Also, while low mood is aroused when efforts to reach a goal are proving futile, continued pursuit of an unapproachable aim can escalate low mood into clinical depression $[10,22]$.

\section{Discussion}

As said by evolutionary psychology, disorders of emotions result from deregulation of otherwise worthwhile responses. This means that determining whether a particular emotion is normal or abnormal requires understanding the situation in which that emotion is beneficial, the cues that generally regulate it, and the presence or absence of that circumstances [19]. Present DSM diagnostic criteria overlook context and attend only to frequency, severity, and duration of emotional symptoms. While this works well at the extremes and increases diagnostic reliability, it gives no guidance in the more common cases where it is hard to decide if an emotion is normal or not [21]. On the other hand, the functional significance of negative emotions should in no way impede attempts to get rid of them. So, psychiatrists should not be inhibited about relieving nervousness, low mood, and jealousy, even when they are supposed to be normal responses [20]. Back to our discussion, evolutionary psychology and psychiatry has supposed, so far, some specific mechanisms as regards the genesis of depression in human being, like these: 1- Psychic pain theory ( for informing organism to evade painful stresses); 2- Behavioral shutdown model (for circumventing stressful activities); 3- Analytical rumination hypothesis (thinking on existing complications for finding way outs); 4- Depression as a dysregulated adaptation (as an exaggerated tool, especially in accompaniment with neuroticism); 5- Social or group ranking theory ( for accepting lower or available social position in spite of long-term struggles for obtaining higher positions due to probability of subsequent and unavoidable horrible expenses); 6Honest signalling theory ( for getting required help and kindness from others); 7- Familial Bargaining theory (for receiving desired attention and care from mate); 8- Social navigation or niche change theory (for achievement of a new social network or social responsibilities for promotion of genetic adaptation); 9- Prevention of infection (for saving metabolic energy and elevation of immunity); 10- The third ventricle hypothesis ( for declining aggressiveness) [22-26]. Nonetheless, the higher frequency of depression in women, disregard to the aforesaid psychoanalytic and evolutionary explanations, may have an additional evolutionary justification, too, that is based on mate selection, nonetheless from a novel viewpoint. According to this innovative explanation which has not been mentioned before in the field of evolutionary psychology and psychiatry, except than the aforesaid proximate mechanisms for enhancement of sexual selection and choosing mate for ultimate promotion of genetic fitness and genomic promulgation, depression may result from a "passive" ongoing struggle for attainment of a favourite mate. Why passive? Because historically and customarily in the existing cultures, whether in industrialized or unindustrialized societies, males (or their families) at the outset and actively take steps for mate selection (by way of courtship or marriage proposal), not females; as like as active sperms that try or compete to enter into inactive ovule. So, normally, if a woman sees a candidate favourable for her, she should try passively to catch his attention. This fact necessitates more indirect manoeuvres and consumption of energy for obtaining a mate, with no guarantee regarding ultimate earning or proximate attainment. It is as like as trying to yell or talk aloud, ceaselessly, by a voiceless person. On the other hand, while females' option for active selection of mate seems restricted, their suitors can be unlimited. While this fact may compensate to some extent the said limited choice, it is not, over again, guarantee-able or prevailing. Also, in cases with few or no suitors, the situation can be worse because no recompense is imaginable except than ultimate loneliness, particularly in developing nations. It may be supposed that the same situation is applicable concerning men, who may over and over again be upset by rejection of their marriage proposals. But the matter here is a contrast between taking an active role or passive role as regards solving a problem. While the suitor may try actively and repeatedly for attainment of his goal through solicitation, exhibition, boasting, temptation, posing and so on, or shift it recklessly and recurrently, the other one can do nothing except than impassive receipt or rebuttal. Also, while the suitor may balance the refutations by moderating his offers or choices, the other one should wait incessantly for better propositions, which may not be reachable, at all. This situation, while similar to its cellular ancestors, fosters the mentality for engagement of abovementioned mechanisms, like psychic pain theory, analytical rumination hypothesis, honest signalling theory, and social navigation theory for generation of depression. It is somewhat similar to learned helplessness, as well, while the victim feels powerlessness in spite of danger or misery. In this regard, the learned helplessness theory of depression connects depressive phenomena to the experience of uncontrollable events. For instance, when dogs in a laboratory were exposed to electrical shocks from which they could not escape, they showed conducts that differentiated them from dogs that had not been exposed to such uncontrollable happenings. The dogs exposed to the shocks would not cross a barrier to stop the flow of electric shock when put in a new learning situation. They remained passive and did not move. According to the learned helplessness theory, the shocked dogs learned that aftermaths were independent of responses, so they had both cognitive motivational deficit (i.e., they would not attempt to escape the shock) and emotional deficit (indicating decreased reactivity to the shock). In the reformulated view of learned helplessness as applied to human depression, internal causal explanations are thought to produce a loss of self-esteem 
after adverse external events. Behaviourists, who subscribe to the theory, stress that improvement of depression is contingent on the patient's learning a sense of control and mastery of the environment [27]. Emotionality of human being is one aspect of behavior that is principally unable to get along with inactivity and passivity, because it may alarm an impending difficulty. When such a problem is regarding sexual selection and picking mate for survival of genetic pools, meaning the ultimate goal of life, then, biologically and evolutionarily, social or interactive inertia may mean nothing except than annihilation of genetic reservoir. While evolution of brain throughout history has been cultural as well as biological, unidirectional activity may deny the first development on behalf of the second progression, and since, according to some scholars, cultural advancement has been historically further than biological evolution [28-31], so an interior mismatch may have taken place between different aspects of mind's evolution. If so, then what could be the resolution? Maybe the solution could be supportive encouragement of more directness and assertiveness in a woman, who consciously or unconsciously feels threat with respect to her ultimate genetic fitness, mate and marriage. While such an inspiration may not be free from some social expenses and depends on set of circumstances, it is applicable regarding the helpseekers who have the guts to do that but are uncertain. Essentially the best consequences of supportive psychotherapy or counselling are with respect to undecided patients who only need a push for falling into a pathway which has been appeared previously in their own minds. Such an assertiveness which may change the public role from an impassive or submissive candidate to a dynamic suitor, or from a pathetic prey to an energetic predator, may resolve suitably the said evolutionary discrepancy or one-sidedness.

Anyway, the evolutionary foundations for psychiatry deliver a valuable framework for understanding behavior, interactions, and passions. Clinicians who comprehend the evolutionary backgrounds and functions of feelings have apparatuses that permit them to better understand ailments of emotions [22]. Therefore, those who apprehend the evolutionary roots of capacities for associations are better able to deal with problematic interactions and the excitements they provoke. Likewise, those who recognize how natural selection has melded extreme prosocial tendencies in humans are better able to comprehend social anxiety and neurosis. Similarly, those who distinguish personality features as social schemes have a basis for understanding personality disorders [23]. Nevertheless, knowing that even negative feelings are beneficial proposes that medications relieving aversive emotions are like treatments that relieve cough or fever by blocking normal intermediating mechanisms [10]. Thus, henceforth, psychotherapists and counsellors may analyze social roles and conflicts that almost invariably involve struggles to get important reproductive resources, and trade-offs among conflicting strategies, roles, and relationships [11].

\section{Acknowledgements}

None.

\section{Conflict of Interest}

Author declare no conflict of interest.

\section{References}

1. Markowitz JC, Milrod B (2017) Mood Disorders: Intrapsychic and Interpersonal Aspects. In: Sadock BJ, Sadock VA, Ruiz P, (eds). Kaplan \& Sadock's Comprehensive Textbook of Psychiatry: 4263-4275.

2. Bromet E, Andrade LH, Hwang I, Sampson NA, Alonso J, et al. (2011) Cross-national epidemiology of DSM-IV major depressive episode. BMC Med 9: 90.

3. Waraich P, Goldner EM, Somers JM, Hsu L (2004) Prevalence and incidence studies of mood disorders: a systematic review of the literature. Can J Psychiatry 49(2): 124-138.

4. Avenevoli S, Swendsen J, He JP, Burstein M, Merikangas KR (2015) Major depression in the national comorbidity survey-adolescent supplement: prevalence, correlates, and treatment. J Am Acad Child Adolesc Psychiatry 54(1): 37-44.

5. Rihmer Z, Szádóczky E, Füredi J, Kiss K, Papp ZS (2001) Anxiety disorders comorbidity in bipolar I, bipolar II and unipolar major depression: results from a population-based study in Hungary. J Affect Disord 67(13): $175-179$.

6. Murphy JM, Gilman SE, Lesage A, Horton NJ, Rasic D, et al. (2010) Time trends in mortality associated with depression: findings from the Stirling County study. Can J Psychiatry 55(12): 776-783.

7. Beach SRH, Kogan SM, Brody GH, Chen YF, Lei MK, et al. (2008) Change in caregiver depression as a function of the Strong African American Families Program. J Fam Psychol 22(2): 241-252.

8. Shoja Shafti S (2018) Psychoanalytic Analysis of Psychopathology. Jami Publishing Company, Tehran.

9. Lorenzo-Luaces L, German RE, DeRubeis RJ (2014) It's complicated: the relation between cognitive change procedures, cognitive change, and symptom change in cognitive therapy for depression. Clin Psychol Rev 41: 3-15.

10. Nesse RM (2017) Evolutionary Foundations for Psychiatric Research and Practice. In: Sadock BJ, Sadock VA, Ruiz P (Eds). Kaplan \& Sadock's Comprehensive Textbook of Psychiatry. ( $10^{\text {th }}$ edn), Wolters Kluwer, USA, pp. 2016-2044.

11. Lipton JE, Barash DP (2009) Sociobiology and Psychiatry. In: Sadock BJ, Sadock VA, Ruiz P (Eds). Kaplan \& Sadock's Comprehensive Textbook of Psychiatry. ( $9^{\text {th }}$ edn), Lippincott Williams \& Wilkins, UA, pp. 716.

12. (2015) Sadock BJ, Sadock VA, Ruiz P (Eds). Sociobiology and Ethology. Kaplan \& Sadock's Synopsis of Psychiatry. ( $11^{\text {th }}$ edn), Lippincott Wolters Kluwer, USA, pp. 131-151

13. Alcock J (2001) The Triumph of Sociobiology. Oxford University Press, New York, USA.

14. Brüne M (2016) Textbook of Evolutionary Psychiatry: The Origins of Psychopathology. ( $2^{\text {nd }}$ edn). Oxford University Press, New York, USA.

15. Brüne M, Belsky J, Fabrega H, Feierman HR, Gilbert P, et al. (2012) The crisis of psychiatry-insights and prospects from evolutionary theory. World Psychiatry 11(1): 55-57.

16. Crespi B (2014) An evolutionary framework for psychological maladaptation's. Psychological Inquiry 25(3-4): 322-324.

17. Del Giudice M, Ellis BJ, Cicchetti D (2014) Evolutionary foundations of developmental psychopathology. Developmental Psychopathology: 1.

18. Fried EI, Nesse RM (2015) Depression sum-scores don't add up: why analyzing specific depression symptoms is essential. BMC Medicine 1(1): 72 .

19. Gilbert P, Bailey KG (2000) Genes on the Couch: Explorations in Evolutionary Psychotherapy. Taylor \& Francis, USA. 
20. Nesse RM (2015) Evolutionary Psychology and Mental Health. In: D Buss (Ed), The Evolutionary Psychology Handbook. (2 ${ }^{\text {nd }}$ edn), Integrations, John Wiley and Sons, USA, pp. 1007-1026.

21. Nesse RM, Ellsworth PC (2009) Evolution, emotions, and emotional disorders. Am Psychol 64(2): 129-139.

22. Wenegrat B (1990) Sociobiological Psychiatry: A New Conceptual Framework. Lexington, USA.

23. Price J, Sloman L, Gardner R, Gilbert P, Rohde P (1994) The social competition hypothesis of depression. Br J Psychiatry 164(3): 309-315.

24. Troisi A (2012) Mental health and well-being: clinical applications of Darwinian psychiatry. Applied Evolutionary Psychology: 276.

25. Allen N, Badcock P (2006) Darwinian Models of depression: A Review of Evolutionary Accounts of Mood and Mood disorders. Prog Neuropsychopharmacol Biol Psychiatry 30(5): 815-826.

26. Gilbert P (2006) Evolution and Depression: Issues and Implications. Psychol Med 36(3): 287-297.
27. (2015) Sadock BJ, Sadock VA, Ruiz P (Eds), Mood Disorders: Learned Helplessness. Kaplan \& Sadock's Synopsis of Psychiatry. (11 ${ }^{\text {th }}$ edn), Lippincott Wolters Kluwer, USA, pp. 356.

28. Vygotsky LS (1978) Mind in Society: The Development of Higher Psychological Processes. Harvard University Press, USA.

29. Shoja Shafti S (2018) Review of Cultural-Historical Psychology. Qoqnoos Publishing Company, Tehran.

30. Shoja Shafti S (2003) An Introduction to Sociobiology (Neo-Darwinism). Qoqnoos Publishing Company, Tehran.

31. Shoja Shafti S (2016) An Introduction to Clinical Sociobiology: Evolutionary Psychology, Psychiatry and Psychotherapy. Qoqnoos Publishing Company, Tehran. 